\title{
O ENSINO FORMAL DE SOFTWARES EM CURSOS DE DESIGN GRÁFICO: UMA PRESENÇA FRAGMENTADA
}

\author{
Marco André Mazzarotto Filho \\ UFPR e UTFPR \\ marcomazzarotto@gmail.com \\ Vania Ribas Ulbricht \\ UFPR e UFSC \\ vrulbricht@gmail.com
}

Resumo: O objetivo deste trabalho foi identificar como o ensino de softwares é formalmente abordado em cursos na área de design gráfico de universidades públicas brasileiras. Como método, utiliza uma pesquisa documental nos Projetos Pedagógicos dos Cursos (PPCs) e ementas das disciplinas. Como resultado, identifica que o ensino desses conteúdos é uma prática presente, porém na maioria dos casos tende a ocorrer de forma fragmentada e descontextualizada, através de disciplinas isoladas e focadas apenas na ferramenta e não na sua aplicação dentro da prática do design gráfico.

Palavras-chave: softwares gráficos, design gráfico, interdisciplinaridade

\begin{abstract}
The aim of this study was to identify how softwares are formally teached in graphic design majors of national public universities. It uses a documentary research on the pedagogical projects of the courses (PPCS) and discipline's syllabus. As result it identifies that education on this topic tends mostly to occur in a fragmented and decontextualized manner, through isolated disciplines focused mainly in the tool and not in your application within graphic design practice.
\end{abstract}

Keywords: graphic softwares, graphic design, interdisciplinarity 


\section{INTRODUÇÃO}

Para Goldschmidt \& Potter (1999) não existe atividade de design sem representação, já que as ideias precisam ser representadas para que possam ser compartilhadas com outros. Diferentes técnicas de representação podem, segundo Matté (2009), ser encontradas ao longo do processo de design, desde os esboços livres das etapas iniciais até às representações detalhadas para as etapas finais de produção. É principalmente nesses momentos finais em que as ideias precisam ser representadas de forma mais propícia para a comunicação, produção e distribuição, que o uso do computador e de softwares gráficos é importante. Como afirma Rosselli (2012), essas tecnologias permitem grande precisão na execução das tarefas, possibilidade em corrigir e reproduzir os desenhos, facilidade de armazenamento e distribuição e uma maior facilidade na execução de técnicas que antes demandavam grande habilidade manual.

Essa importância das habilidades em representação gráfica através do uso de softwares pode ser atestada pela demanda de empresas de design por profissionais que já dominem essas técnicas e ferramentas, como apontam as pesquisas conduzidas por Yang et al (2005) em Taiwan, Valente \& Almeida Neto (2006) no Brasil, Erkarslan et al (2011) na Turquia e Dobson (2014) na Inglaterra. Essa demanda do mercado reflete na expectativa dos estudantes com a formação ofertada por suas instituições de ensino, pois, como apontam Marshall \& Meachem (2007) e Buery (2013), a maioria dos alunos considera o ensino do uso de softwares uma parte importante dos seus cursos.

Porém, o ensino de softwares gráficos não pode ocorrer, como afirma Marshall (2004), de forma abstrata e separada do processo de design. Para a autora, transmitir conhecimentos ferramentais no uso de softwares desconectados de preocupações com habilidades de resolução de problemas e de comunicação visual, é, utilizando uma metáfora, o equivalente a uma pessoa que, mesmo conhecendo todas as palavras, é incapaz de formar frases conexas e se fazer entender.

É nesse contexto formado por um lado pela necessidade dos futuros designers apresentarem competência no uso de softwares para representação gráfica digital, e por outro que esse uso não seja descontextualizado, mas sim conectado com a prática do design, que a presente pesquisa se encontra. $O$ objetivo geral deste trabalho foi identificar como o ensino de softwares é formalmente abordado em cursos na área de design gráfico de universidades públicas brasileiras. De forma mais detalhada, procura dois objetivos específicos: (a) identificar a quantidade e características das disciplinas envolvendo o ensino de softwares; (b) identificar se existem e como são as estratégias de integração do ensino de softwares com outros conteúdos específicos de design gráfico.

\section{O ENSINO DE SOFTWARE EM CURSOS DE DESIGN DE GRÁFICO}

Marshall \& Meachem (2007) apontam que a inserção do ensino de softwares em cursos de design no final da década de 90 foi mais reativa do que proativa. Para as autoras, as instituições inseriram esses conteúdos em seus currículos como uma resposta às pressões de alunos e do mercado, e não devido a um entendimento de como seria a melhor forma de integrá-lo dentro da formação de um designer gráfico. Como resultado, o ensino desses conteúdos foi na sua maioria estruturado na forma de disciplinas isoladas, ensinadas dentro de laboratórios de informática, e completamente separado da prática projetual que ocorre nos estúdios, ateliers e outros espaços da universidade. 
Trazendo a discussão para o contexto nacional, Spitz (1995) aponta a mesma tendência. Segundo a autora, embora a computação gráfica tenha se consolidado como uma disciplina obrigatória nos currículos brasileiros, é comum encontra-la totalmente desvinculada das demais, alocadas em laboratórios especiais, dentro ou fora dos departamentos, mas invariavelmente isolados da poeira, argila, vernizes e tintas e de outros materiais que fazem parte do cotidiano do design.

Para Stout (1996) apud Marshall (2007), é fundamental integrar as competências já tradicionais do design com as novas tecnologias, caso contrário corre-se o risco de criar usando metáforas e uma linguagem informal - 'macacos de computador', muito bons em usar as tecnologias, mas deixando o 'rabo balançar o cachorro', já que ao não terem um entendimento claro de como organizar textos e elementos para criar uma mensagem eficaz, deixam o computador cuidar disso por eles.

Nesse sentido, Marshall \& Meachem (2007) concluem que o ensino da prática projetual em conjunto com as novas tecnologias é a forma mais apropriada de trabalhar tanto assuntos referentes ao design quanto ao aprendizado de softwares. Nesse contexto integrado, estudantes desenvolvem um entendimento de como utilizar os softwares dentro de um processo de geração de ideias e resolução de problemas, fortalecendo cada uma dessas habilidades ao mesmo tempo que reforçam a integração entre elas.

\section{MÉTODO}

Para identificar como o ensino de softwares ocorre atualmente em cursos de design gráfico, o método estruturado consiste de uma pesquisa documental, na qual as principais fontes de evidências foram os projetos pedagógicos dos cursos (PPCs), planos de ensino e ementas das disciplinas. A condução do método foi dividida em três etapas: (1) identificação dos cursos; (2) busca e organização dos documentos; (3) análise e tabulação dos resultados.

A identificação dos cursos foi realizada através do mecanismo de busca do portal eMEC (http://emec.mec.gov.br/), utilizando a aba "Busca Avançada". Nela foram definidas as opções "Busca por curso", "sim" para gratuidade e apenas para os cursos "em atividade". As palavras chaves utilizadas para o nome do curso foram "Design", "Comunicação visual" e "Desenho Industrial". Ao final do processo, foram identificados trinte e seis cursos, sendo dezoito bacharelados específicos na área de design gráfico, quatorze bacharelados generalistas e quatro cursos de tecnologia em design gráfico.

A etapa seguinte, com o objetivo de buscar os documentos necessários, foi executada principalmente através dos websites dos cursos. Para os cursos que não disponibilizaram esses documentos em seus websites, foi feita ainda uma tentativa de encontra-los através do mecanismo de busca do Google. Ao final, não foi possível levantar os documentos necessários para dez dos cursos previamente identificados, que foram, portanto, excluídos da análise.

A análise dos documentos foi feita em duas partes. Primeiro os documentos foram lidos em busca das disciplinas que faziam menção ao ensino de softwares. Conforme as disciplinas eram identificadas, as informações referentes a elas eram transferidas para um documento que as reunia. Após esse levantamento, a análise foi aplicada de forma dinâmica, com leituras seguidas dos dados na busca por identificar padrões e formar as categorias de análise. Os resultados dessa categorização são apresentados a seguir. 


\section{RESULTADOS}

\subsection{Quantidade de disciplinas por curso}

Como pode ser observado na tabela 1 , foram identificadas entre todos os cursos um total de oitenta e sete disciplinas cujas as ementas fazem menção ao ensino de softwares. Esse total inclui disciplinas obrigatórias e optativas. Também abrange tanto disciplinas majoritariamente focadas no ensino de softwares quanto aquelas onde esse tema ocorre em conjunto com outros. Esse total representa uma média de 3,4 disciplinas por curso, mas como aponta o desvio padrão de 2,95, há variação entre cursos com menos ou mais disciplinas que a média. Analisando os tipos de curso de forma separada, percebe-se que a média geral se mantém próxima às médias dos bacharelados generalistas (3,4 disciplinas) e específicos em design gráfico (3,6 disciplinas). Apenas os cursos de tecnologia apresentam um valor diferente, média de 2 disciplinas por curso, com desvio padrão 0 .

Tabela 1 - Quantidade de disciplinas que abordam o ensino de softwares

\begin{tabular}{lllll}
\hline & CURSOS & DISCIPLINAS & MÉDIA & $\begin{array}{l}\text { DESVIO } \\
\text { PADRÃO }\end{array}$ \\
\hline Bacharelado generalista & 10 & 34 & 3,4 & 2,27 \\
\hline $\begin{array}{l}\text { Bacharelado específico } \\
\text { em design gráfico }\end{array}$ & 13 & 47 & 3,6 & 3,71 \\
\hline Tecnologia em design gráfico & 3 & 6 & 2,0 & 0 \\
\hline Total & 26 & 87 & 3,3 & 2,95 \\
\hline
\end{tabular}

Fonte: Elaborado pelo autor, com base na pesquisa realizada

Como forma de apresentar uma visão mais precisa da quantidade de disciplinas que os cursos possuem, a figura 1 apresenta a distribuição ao longo de quatro categorias: aqueles que não apresentam nenhuma disciplina, e os que apresentam uma ou duas, três ou quatro e cinco ou mais disciplinas. Essa distribuição foi feita tanto para o total de cursos quanto de forma específica para cada tipo. Como pode ser observado, todos os cursos apresentam pelo menos uma disciplina relacionada ao ensino de softwares, sendo que o mais comum é que apresentem entre uma ou duas disciplinas (50\%, 13 cursos). Os cursos que apresentam entre três e quatro somaram $30,8 \%$ (8 cursos), enquanto os que apresentam cinco ou mais representam 19,2\% (5 cursos). Comparando as diferenças entre os diferentes tipos de curso, a mais notável é que nenhum curso de tecnologia apresentou mais de duas disciplinas voltadas para o ensino de softwares.
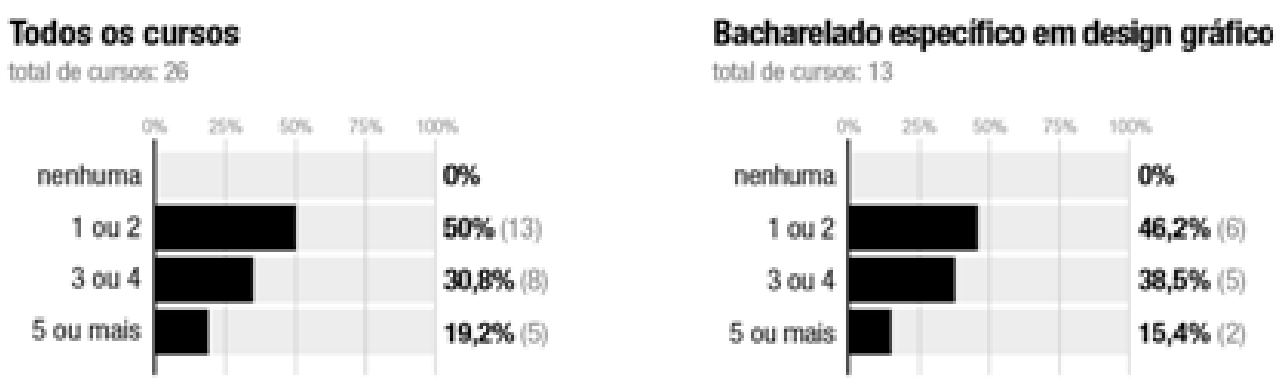
Bacharelado generalista

total de cursos: 10

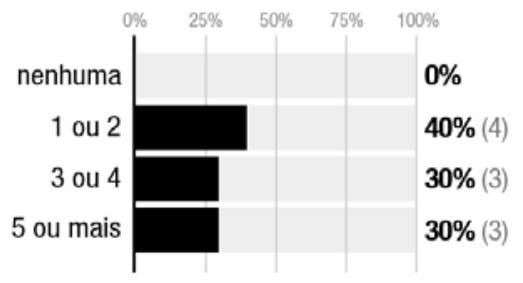

Tecnologia em design gráfico

total de cursos: 3

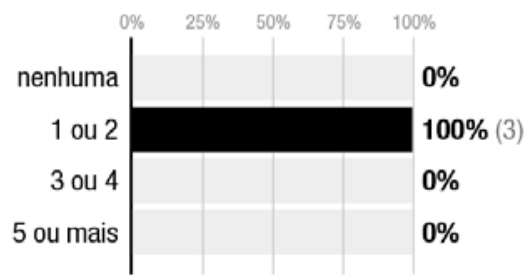

Figura 1 - Quantidade por curso de disciplinas que abordam o ensino de softwares.

Fonte: Elaborado pelo autor, com base na pesquisa realizada

\subsection{Tipos de disciplinas ministradas}

Ao longo na análise documental foram formuladas duas categorias para a classificação das disciplinas. A primeira diz respeito a sua obrigatoriedade ou não para a formação do aluno, podendo ser uma disciplina do tipo obrigatória ou do tipo optativa.

Já a segunda é referente a forma como o ensino de softwares está descrito na ementa, se descontextualizado e focado apenas no uso da ferramenta ou se integrado a outros conteúdos, possuindo seu ensino previsto de forma contextualizada com outras competências e temas referentes a prática do design. No quadro 1 são apresentados exemplos dessas duas classificações. A disciplina de “Animação 2D" da UFPE-Caruaru, por exemplo, é do tipo contextualizada, já que na sua ementa o ensino de softwares ocorre em conjunto com temas como processo e história da animação. Já na disciplina de "Tratamento de imagens" da UTFPR, o ensino de softwares para edição de imagens bitmap está previsto de forma isolada, sem nenhuma integração com outros aspectos do design, sendo, portanto, do tipo descontextualizada.

Quadro 1 - Exemplos de ementas de disciplinas dos tipos contextualizada e descontextualizada.

\begin{tabular}{|l|l|l|}
\hline TIPO & FONTE & EMENTA \\
\hline Contextualizada & $\begin{array}{l}\text { Disciplina de Animação 2D do } \\
\text { Bacharelado em Design da UFPE- } \\
\text { Caruaru. }\end{array}$ & $\begin{array}{l}\text { Animação 2D e seus estilos; analógica e } \\
\text { digital; processos da animação 2D; sincronia } \\
\text { labial; história da animação 2D; softwares } \\
\text { de animação, coloração e composição. }\end{array}$ \\
\hline Descontextualizada & $\begin{array}{l}\text { Disciplina de Tratamento de } \\
\text { Imagens do curso de Tecnologia } \\
\text { em Design Gráfico da UTFPR. }\end{array}$ & $\begin{array}{l}\text { Noções e práticas básicas de tecnologias } \\
\text { digitais aplicadas ao tratamento e edição de } \\
\text { imagens digitais estáticas bitmap. }\end{array}$ \\
\hline
\end{tabular}

Fonte: Elaborado pelo autor, com base na pesquisa realizada

Como pode ser observado na figura 2, a maior parte das disciplinas identificadas $(70,1 \%)$ são obrigatórias, enquanto $29,9 \%$ são optativas. Quanto ao contexto de ensino, mais da metade $(59,8 \%)$ são descontextualizadas e voltadas para o ensino isolado de softwares, enquanto no restante $(40,2 \%)$ o ensino é previsto para ocorrer contextualizado, em conjunto com outros conteúdos referentes a prática do design. 


\section{Obrigatoriedade}

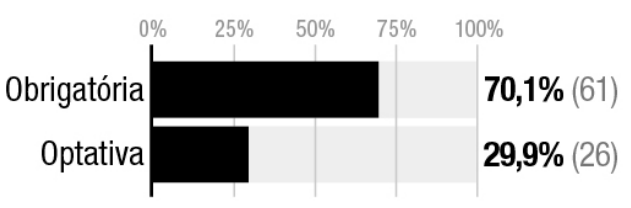

\section{Abordagem dos conteúdos}

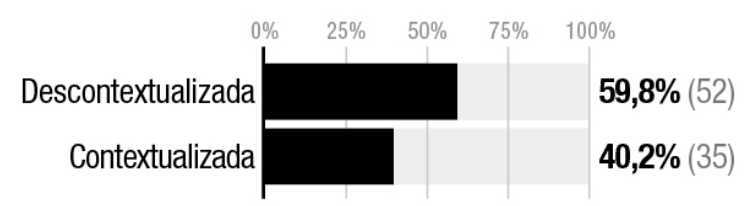

Figura 2 - Tipos de disciplinas que envolvem o ensino de softwares.

Fonte: Elaborado pelo autor, com base na pesquisa realizada

Já a figura 3 apresenta o cruzamento entre essas categorias. Como pode ser observado, o tipo mais comum de disciplina é a obrigatória descontextualizada (51,7\%), enquanto as disciplinas optativas descontextualizadas representam apenas $8 \%$ do total. Já as contextualizadas apresentam números semelhantes, $18,4 \%$ para as obrigatórias e $21,8 \%$ para as optativas.

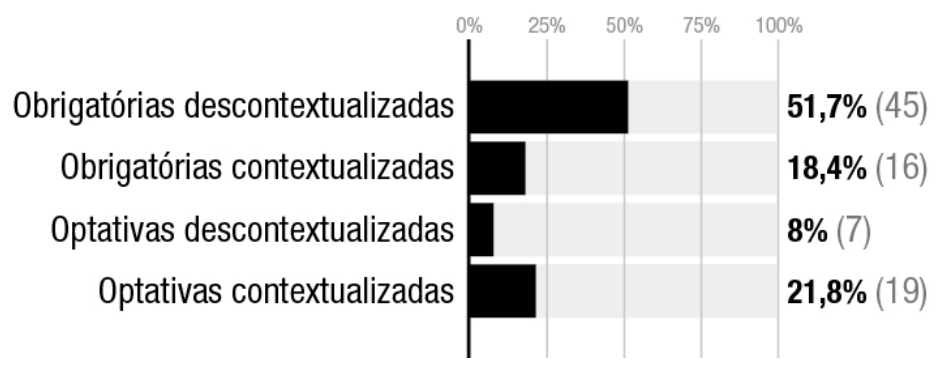

Figura 3 - Cruzamento entre a obrigatoriedade da disciplina e o foco do conteúdo. Fonte: Elaborado pelo autor, com base na pesquisa realizada

\subsection{Carga horária}

A tabela 2 apresenta a média da carga horárias das oitenta e sete disciplinas identificadas. Como pode ser visto na última linha da tabela, elas são compostas em média por 3,46 aulas semanais (desvio padrão: 1 ), tendo carga horária total média de 56,58 horas (desvio padrão: 17,35 ). As disciplinas optativas e as contextualizadas tendem a ser um pouco mais extensas, apresentando na média 67 e 60 horas respectivamente, contra 54,2 e 56,3 horas das obrigatórias e descontextualizadas.

Tabela 2 - Carga horária das disciplinas

\begin{tabular}{lllll}
\hline & \multicolumn{2}{l}{ No DE AULAS POR SEMANA } & \multicolumn{2}{c}{ CARGA HORÁRIA DISCIPLINA (H) } \\
& Média & Desvio padrão & Média & Desvio Padrão \\
\hline Obrigatórias & 3,4 & 0,9 & 54,2 & 16,7 \\
\hline Optativas & 4 & 0,6 & 67 & 9,9 \\
\hline Descontextualizadas & 3,4 & 0,9 & 56,3 & 16,1 \\
\hline Contextualizadas & 3,8 & 0,9 & 60,5 & 15,9 \\
\hline Total & 3,46 & 1 & 56,58 & 17,35 \\
\hline
\end{tabular}

Fonte: Elaborado pelo autor, com base na pesquisa realizada

Já a tabela 3 apresenta a discriminação por curso e instituição das cargas horárias obrigatórias das disciplinas que envolvem o ensino de softwares, além da porcentagem que essas cargas horárias representam no total da graduação. Como pode ser observado, 
se antes não foram encontrados cursos sem nenhuma disciplina que envolvesse o ensino de softwares, agora é possível identificar que existem três cursos onde não há nenhuma disciplina obrigatória nessa área (UFPel e UFPE Recife e Caruaru). Também é possível notar que existem sete cursos que não oferecem nenhuma disciplina obrigatória descontextualizada no ensino de softwares (os três citados anteriormente, mais USP, UERJ, UFC e UFMG). Já às obrigatórias contextualizadas são minoria, sendo ofertadas em apenas dez instituições.

Tabela 3 - Carga horária das disciplinas obrigatórias por curso

\begin{tabular}{|c|c|c|c|c|c|c|}
\hline & $\begin{array}{l}\text { Tipo de } \\
\text { curso }\end{array}$ & $\begin{array}{l}\text { Carga } \\
\text { horária } \\
\text { total (h) }\end{array}$ & $\begin{array}{l}\text { Obrigatórias } \\
\text { focadas(h) }\end{array}$ & $\begin{array}{l}\text { Obrigatórias } \\
\text { não focadas(h) }\end{array}$ & $\begin{array}{l}\text { Total obrigatórias } \\
\text { (h) }\end{array}$ & $\begin{array}{l}\% \text { em } \\
\text { relação a } \\
\text { C.H. total }\end{array}$ \\
\hline UFPE Recife & BG & 3040 & 0 & 0 & 0 & $0,0 \%$ \\
\hline UFPE Caruaru & BG & 3600 & 0 & 0 & 0 & $0,0 \%$ \\
\hline UFPel & BDG & 2166 & 0 & 0 & 0 & $0,0 \%$ \\
\hline UFAL & BG & 3870 & 45 & 0 & 45 & $1,2 \%$ \\
\hline UNESP & BDG & 2400 & 30 & 0 & 30 & $1,3 \%$ \\
\hline USP & BG & 3870 & 0 & 60 & 60 & $1,6 \%$ \\
\hline UERJ & BG & 3600 & 0 & 60 & 60 & $1,7 \%$ \\
\hline UFC & BDG & 3200 & 0 & 64 & 64 & $2,0 \%$ \\
\hline UNEB & BDG & 2865 & 60 & 0 & 60 & $2,1 \%$ \\
\hline UFES & BDG & 2790 & 120 & 0 & 120 & $4,3 \%$ \\
\hline UFSC & BDG & 2925 & 126 & 0 & 126 & $4,3 \%$ \\
\hline UFG & BDG & 2719 & 64 & 64 & 128 & $4,7 \%$ \\
\hline UTFPR & $\mathrm{T}$ & 2775 & 51 & 85 & 136 & $4,9 \%$ \\
\hline UFMG & $B G$ & 2700 & 0 & 150 & 150 & $5,6 \%$ \\
\hline UTFPR & BG & 3405 & 195 & 0 & 195 & $5,7 \%$ \\
\hline UFAM & BG & 3105 & 120 & 60 & 180 & $5,8 \%$ \\
\hline UEL & BDG & 2915 & 170 & 0 & 170 & $5,8 \%$ \\
\hline UFRGS & BDG & 3975 & 240 & 0 & 240 & $6,0 \%$ \\
\hline IFPB & $\mathrm{T}$ & 2166 & 134 & 0 & 134 & $6,2 \%$ \\
\hline UDESC & BDG & 3240 & 216 & 0 & 216 & $6,7 \%$ \\
\hline UFJF & BG & 3300 & 195 & 45 & 240 & $7,3 \%$ \\
\hline IFFluminense & $\mathrm{T}$ & 2116 & 160 & 0 & 160 & $7,6 \%$ \\
\hline UFRJ & BDG & 2580 & 60 & 150 & 210 & $8,1 \%$ \\
\hline UFRGN & BDG & 2690 & 180 & 60 & 240 & $8,9 \%$ \\
\hline IFsul & BG & 2920 & 285 & 0 & 285 & $9,8 \%$ \\
\hline UNB & BDG & & scipli & do curso não fo & m encontradas. & \\
\hline
\end{tabular}

BG = Bacharelado generalista / BDG = Bacharelado em design gráfico / T = Tecnologia em design gráfico Fonte: Elaborado pelo autor, com base na pesquisa realizada

Ainda na tabela 3, referente a porcentagem que as disciplinas que envolvem o ensino de software representem em comparação a carga horária total do curso, é possível 
notar que não existem um padrão entre as instituições. Treze delas apresentam porcentagens que variam entre $0 \%$ e $4,9 \%$, enquanto 12 apresentam números entre $5,0 \%$ e $9,8 \%$.

\subsection{Períodos nos quais são ofertadas}

O gráfico representado na figura 4 apresenta a distribuição das disciplinas obrigatórias (tanto contextualizadas como descontextualizadas) ao longo dos períodos dos cursos. São consideradas apenas as disciplinas obrigatórias em função das optativas normalmente não terem um período específico para serem cursadas. Como pode ser observado, a maior parte das disciplinas é ofertada no 3 o período $(31,8 \%)$, seguido pelo 2 은 $(21,2 \%)$ e 4 ㅇ (16,7\%). Poucas ocorrem no 1 ํ período, apenas $6,1 \%$.

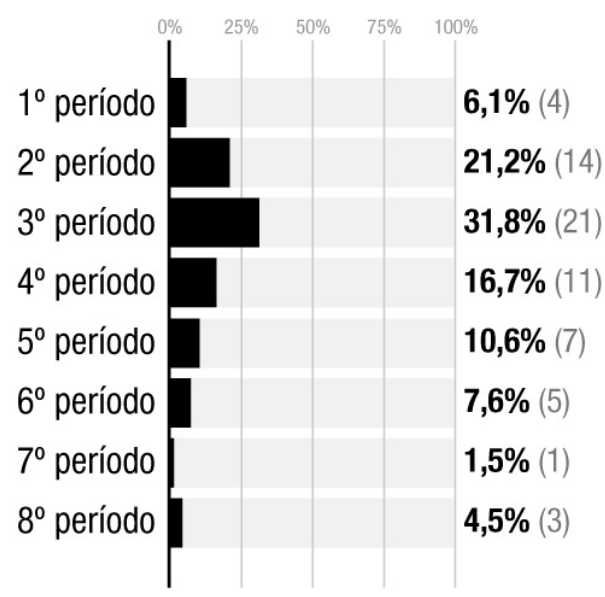

Figura 4 - Distribuição das disciplinas obrigatórias ao longo do curso.

Fonte: Elaborado pelo autor, com base na pesquisa realizada

\subsection{Tipos de softwares ensinados}

Analisando as ementas das disciplinas foi possível identificar oito tipos de softwares que são ensinados em cursos de design:

- Desenho vetorial: Softwares 2D utilizados para a produção de imagens prioritariamente vetoriais e peças de design gráfico com uma ou poucas páginas.

- Tratamento de imagem: Softwares 2D utilizados para a produção e edição de imagens bitmap, incluindo fotografias e outros tipos de imagens raster.

- Diagramação: Softwares 2D mais adequados para peças de design gráfico impressas ou digitais com número extenso de páginas, como livros e revistas.

- Webdesign e interfaces: Softwares que auxiliam na produção de páginas HTML ou na prototipação de interfaces.

- Animação: Softwares voltados para a produção de animações em 2D ou 3D.

- Edição: Softwares voltados para a edição de vídeos.

- Desenho técnico: Softwares CAD voltados para a criação de desenhos vetoriais em 2D ou 3D, com foco principalmente em desenhos técnicos de produção.

- Modelagem 3D: Softwares para a produção de imagens tridimensionais, com pouco ênfase em desenhos técnicos de produção, e mais voltados para simulações estéticas de ambientes e produtos ou a criação de personagens e cenários. 
$\mathrm{Na}$ figura 5, é possível observar a quantidade de disciplinas presentes em cada grupo. O gráfico do lado esquerdo apresenta uma visão geral integrando todos os tipos de curso, já o gráfico da direita busca identificar as diferenças no perfil das disciplinas ofertadas em cursos generalistas em comparação com as ofertadas em cursos específicos de design gráfico (incluindo os cursos de bacharelado e de tecnologia juntos).

Analisando primeiro os cursos de forma integrada, é possível observar que a maior parte das disciplinas encontradas envolve o ensino de softwares de modelagem 3D $(36,7 \%)$ e de animação $(30,4 \%)$, seguida pelo ensino de desenho vetorial e tratamento de imagens, ambos presentes em $22,7 \%$ das disciplinas. Softwares voltados para diagramação $(17,7 \%)$ e para desenho técnico $(15,2 \%)$ aparecem em um terceiro patamar, enquanto os voltados para edição $(8,9 \%)$ e webdesign/interfaces $(7,6 \%)$ são os menos abordados.

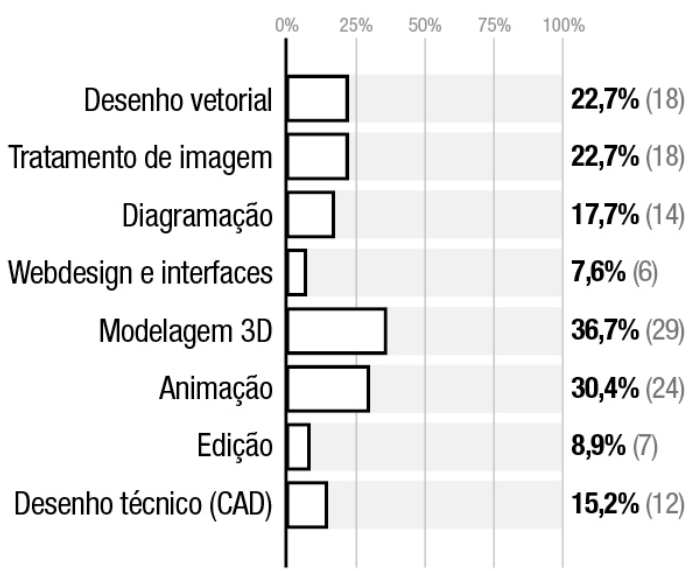

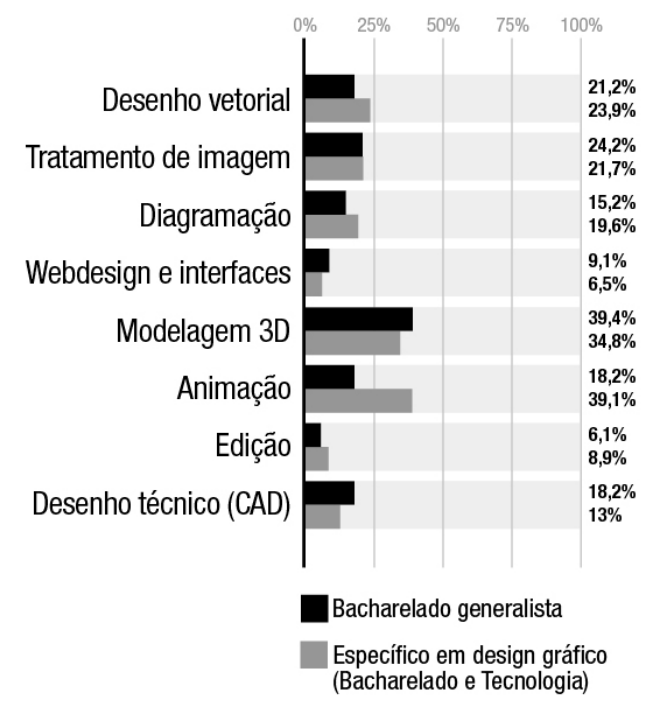

Figura 5 - Tipos de softwares ensinados nas disciplinas.

Fonte: Elaborado pelo autor, com base na pesquisa realizada

Quanto as diferenças entre os cursos generalistas e os específicos em design gráfico, a mais notória está na categoria animação, que é a mais ensinada nos cursos de design gráfico (39,1\% das disciplinas) e a quarta mais ensinada nos generalistas $(18,2 \%$, empatada com desenho técnico). Modelagem 3D (39,4\% contra 34,8\%) e desenho técnico $(18,2 \%$ contra $13 \%)$ costumam estar um pouco mais presentes nos cursos generalistas. Já softwares voltados para diagramação são um pouco mais presentes nos cursos específicos para design gráfico $(19,6 \%$ contra $15,2 \%)$. Nas outras categorias as diferenças são inferiores a $3 \%$.

Ainda em relação aos tipos de softwares ensinados, a figura 6 apresenta um cruzamento destas categorias com os tipos de disciplinas (obrigatórias/optativas e contextualizadas/descontextualizadas). Como pode ser observado, desenho vetorial, tratamento de imagem e diagramação são fundamentalmente ensinados através de disciplinas descontextualizadas e focadas apenas no uso da ferramenta, com a porcentagens de disciplinas desse tipo oscilando entre $85 \%$ e $90 \%$. Softwares para webdesign, modelagem 3D e desenho técnico também são na sua maioria ensinados através de disciplinas obrigatórias e descontextualizadas, mas com números na casa dos dois terços. De modo oposto, softwares para animação $(29,2 \%)$ e edição (0\%) raramente são ensinados fora dos contextos destes conteúdos, sendo, portanto, trabalhados em disciplinas em conjunto com outros temas pertinentes ao design. 


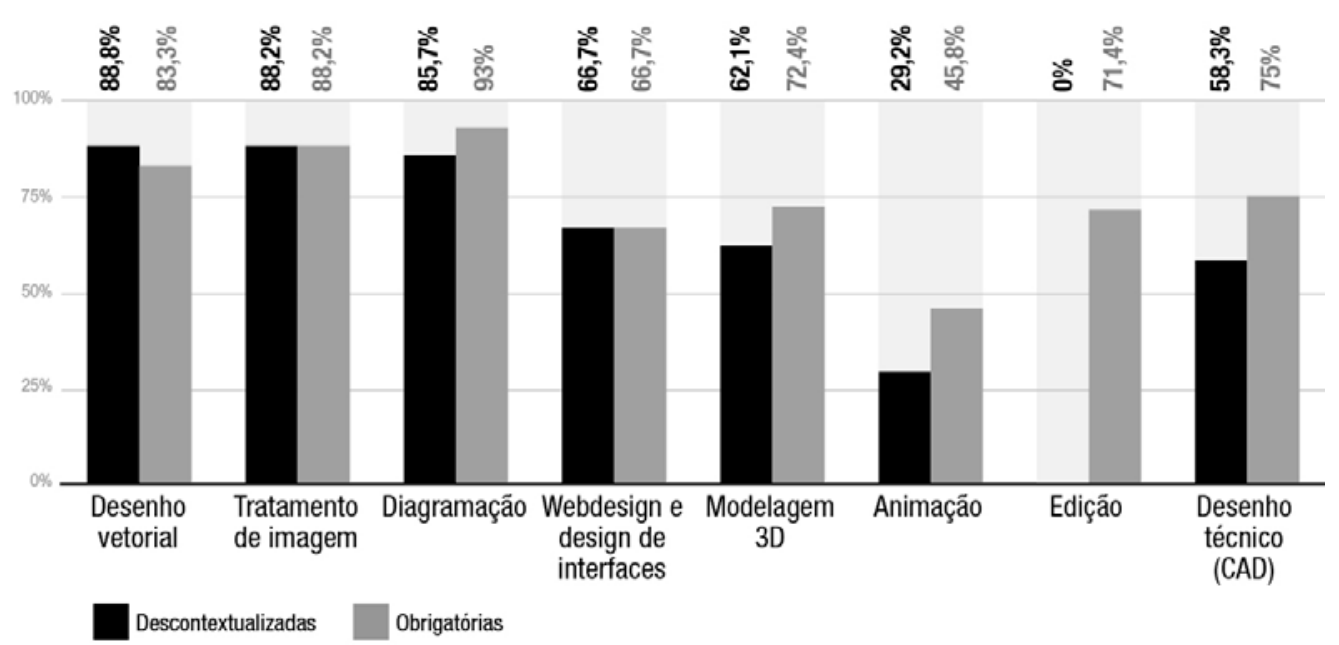

Figura 6 - Tipos de disciplinas utilizadas para o ensino de cada tipo de software.

Fonte: Elaborado pelo autor, com base na pesquisa realizada

\subsection{Integração entre o ensino de software e outros conteúdos de design.}

Do ponto de vista do ensino formal, pautado pelos PPCs e ementas das disciplinas, entende-se que a integração entre o ensino de softwares com outros conteúdos e habilidades de design podem ocorrer de duas maneiras: (a) através da integração entre disciplinas diferentes ou (b) através da integração de conteúdos dentro de uma mesma disciplina, ou seja, através de uma disciplina contextualizada.

A primeira estratégia, formada pela integração interdisciplinar de disciplinas de software com outras mais voltadas para questões específicas do design gráfico, foi identificada apenas no curso ofertado pela UFSC. No PPC deste curso, é possível notar que as disciplinas de projeto precisam ser cursadas em conjunto com outras disciplinas de suporte, onde é possível encontrar disciplinas voltadas para o ensino de software. Um exemplo é o do grupo formado pelas disciplinas Projeto 5 (prática de projeto gráfico editorial), que ocorre de forma integrada com as disciplinas de Produção Gráfica, Tipografia e Produção Editorial (e nesta, além do ensino de conteúdos voltados para o planejamento visual de publicações, encontra-se também o ensino de softwares específicos para diagramação). Esse nível de interdisciplinaridade incluindo o ensino de softwares com outras disciplinas de design não foi encontrado em mais nenhuma das ementas ou PPCs dos vinte e cinco cursos restantes.

Quanto à integração de conteúdos dentro de uma mesma disciplina, é importante que em um primeiro momento tanto os conteúdos voltados para o ensino de softwares quanto para outras habilidades e conhecimentos estejam previstos na ementa da mesma disciplina. Dito isso, a possibilidade dessa integração é maior nas disciplinas contextualizadas, já que nas descontextualizadas está previsto apenas o ensino isolado da ferramenta. Retornando para o gráfico da figura 5, é relevante notar que a tendência de ensino de disciplinas descontextualizadas é maior, com 59,8\% sendo previstas desta forma. Esse número, porém, esconde a grande diferença de abordagem conforme o tipo de software abordado. Softwares básicos para a prática do design gráfico, como os de desenho vetorial, tratamento de imagem e diagramação, raramente tem o seu ensino previsto de maneira conjunta com outras habilidades e conhecimentos, e devem estar sendo ensinados de maneira isolada em torno dos $90 \%$ dessas disciplinas. De maneira oposta, há uma tendência bem maior de softwares de animação e edição serem 
trabalhados de forma integradas com outros conteúdos destas áreas, já que $70,8 \%$ e 100\% respectivamente destas disciplinas são contextualizadas.

É relevante debater, porém, que a simples existência de conteúdos previstos na mesma disciplina não é garantia de um ensino integrado destes conteúdos, porém parece evidente que essa prática é facilitada nesses casos. Da mesma forma, a existência de disciplinas apenas focadas por suas ementas no ensino de softwares não torna impossível a integração desses conteúdos com outros, mas deve dificultar essa prática, já que demanda um esforço extra do professor para ir além do previsto.

\section{CONSIDERAÇÕES FINAIS}

O ensino formal de softwares gráficos, ou seja, o ensino previsto pelos PPCs e ementas das disciplinas, é uma prática presente, em maior ou menor grau, em todos os vinte e seis cursos de instituições públicas analisados neste trabalho. Metade dos cursos tem entre uma e duas disciplinas envolvendo o ensino de softwares, enquanto $30,8 \%$ apresentam entre três e quatro e o restante cinco ou mais disciplinas. Na média, os cursos apresentam 3,3 disciplinas, com desvio padrão de 2,95. Usualmente, são disciplinas de 3 a 4 aulas semanais, e são ofertadas com maior frequência no 3 o período $(31,8 \%$ das disciplinas) seguido pelo 20 (21,2\%) e 4으 períodos $(16,7 \%)$.

As disciplinas obrigatórias (70,1\%) são mais comuns em relação às optativas (29,9\%). Três cursos não possuem nenhuma disciplina obrigatória envolvendo o ensino de softwares. Nos demais, a porcentagem de participação das disciplinas obrigatórias de software na carga horária total do curso variou de 1,2\% a 9,8\%.

Esses resultados apontam para a confirmação da tendência de ensino formal de softwares previsto dentro dos cursos da área de design gráfico.

Já as disciplinas descontextualizadas, focadas em suas ementas apenas no ensino da ferramenta, correspondem a $59,8 \%$ do total. Neste tipo de disciplina, acredita-se que existe uma tendência maior que o ensino seja isolado de outros conteúdos de design, já que estes não se encontram previstos na ementa. Disciplinas que abordam softwares básicos e importantes para a formação do designer gráfico, como desenho vetorial, tratamento de imagem e diagramação, ocorrem principalmente através de disciplinas descontextualizadas, que correspondem em torno de $85 \%$ a $90 \%$ do total. As disciplinas contextualizadas abordam principalmente o ensino de softwares para animação e edição. Nesses casos, porém, isso pode não ocorrer em função de um entendimento da importância de um processo de aprendizagem integrado e interdisciplinar, mas sim porque em boa parte dos cursos existem apenas uma disciplina para esses assuntos, que acabam então abordando todos os conteúdos.

Quanto a presença de integração interdisciplinar de disciplinas de software com outras, é uma estratégia que foi identificada em apenas um curso.

Dessa forma, o que se percebe é que o ensino de softwares em cursos de design gráfico é uma prática presente, porém fragmentada. Nesse sentido, ainda se mostram válidas as afirmações feitas por Spitz (1995) e Marshall \& Meachem (2007) sobre a tendência predominante da adoção deste ensino através de disciplinas isoladas e pouco conectadas com outros temas referentes a prática do design. Esse ensino focado prioritariamente no software é perigoso, pois como afirma Stout (1996) apud Marshall (2007), corre-se o risco de criar um 'macaco de computador', muito bom em usar as ferramentas tecnológicas, mas incapaz de ter um entendimento claro de como organizar textos e elementos para criar uma mensagem gráfica eficaz. 
Essa constatação, realizada com base na análise dos PPCs e ementas, abre duas novas frentes de pesquisa. A primeira é relacionada a sanar as limitações de uma pesquisa puramente documental, já que a realidade da prática durante a realização das disciplinas pode ser diferente, inclusive apresentando estratégias de integração entre os conteúdos não previstas nos documentos. Já a segunda frente de pesquisa, precisa focar justamente em levantar e avaliar propostas para mitigar essa fragmentação, promovendo processos de ensino e aprendizagem que integrem melhor o uso de softwares e a prática do design.

\section{REFERÊNCIAS}

BUERY, Cristina C. O ensino da representação gráfica digital aplicada ao projeto: o caso da FAU-UFRJ. In: Graphica'13: XXI Simpósio Nacional de Geometria Descritiva e Desenho Técnico. Florianópolis, 2013.

DOBSON, Jenny. RIBA Appointments: Skills Survey Report 2014. In: RIBA Appointments. Newcastle Upon Tyne: RIBA Bookshops, 2014.

ERKARSLAN, Onder; KAYAM Nazife. \& DILEK, Ozgün. Comparative analysis of recruitment qualifications of industrial designers in Turkey through undergraduate education programs and online recruitment resources. In: International Journal of Technology and Design Education. 23, 2001, p. 129-145.

GOLDSCHMIDT, Gabriela, PORTER, William. Design Representation. New York: Springer Verlag, 1999.

MARSHALL, Lindsey. Technological Tools: the Need to Situate Software Skills in the Implementation of Design Concepts. In: IEEE International Conference on Advanced Learning Technologies (ICALT'04), 2004.

MARSHALL, Lindsey \& MEACHEM, Lester. Direct or directed: orchestrating a more harmonious approach to teaching technology within an Art \& Design Higher Education curriculum. In: Learning, Media and Technology. v. 32, n.1, 2007, p. 41-52.

MATTÉ, Volnei A. O Conhecimento da prática projetual dos designers gráficos como base para o desenvolvimento de materiais didáticos impressos. 2009. 304f. Tese (Doutorado) - UFSC, Programa de Pós-Graduação em Engenharia e Gestão do Conhecimento.

ROSSELLI, Bruno. Taxonomia de meios de representação em ambientes multidimensionais e sua aplicação na metodologia projetual. 2012. Dissertação (Mestrado) - Uniritter, Programa de Pós-graduação em Design.

SPITZ, Rejane. Dirty hands on the keyboard. In: Sixth International Symposium on Eletronic Art - ISEA'95, Montreal, 1995.

VALENTE, Vânia \& ALMEIDA NETO, Jayme. Computação Gráfica como ferramenta para profissionais de desenho industrial. In: Educação Gráfica. v. 10, n.1, 2006.

YANG, M. Y., YOU, M., \& CHEN, F. C. Competencies and qualifications for industrial design jobs: Implications for design practice, education, and student career guidance. In: Design Studies, v. 26, n.2, 2005, p. 155-189. 